\title{
NOTE ON THE ANATOMY OF CYSTIDICOLA FARIONIS.
}

\author{
By R. T. LEIPER, M.B., F.Z.S. \\ Helminthologist to the London School of Tropical Medicine.
}

THE nematode worms discovered by Mr Shipley in the swim-bladder of Trout belong to the species Cystidicala farionis, first described by Fischer, and considered by him to represent a new and distinct type in nematode structure for which he proposed the generic name Cystidicola. Later writers refused to accept the new genus and included it in various other groups (see Synonymy, p. 190). In accordance with an old nomenclatural practice the proposed generic name was adopted as the specific name in place of that originally given, thus Cystidicola farionis became, for Rudolphi, Spiroptera cystidicola. From a detailed examination of the various characters of $C$. farionis $\mathrm{I}$ have come to the conclusion that Fischer was correct in creating a new genus for the new forms, and I therefore propose the reinstatement of the abandoned name Cystidicola. It is also in accordance with modern nomenclatural ruling that the original specific name farionis should be adopted in place of cystidicola.

\section{The anatomy of $C$. farionis.}

The body is very slender and translucent, it tapers gradually from the middle third to both ends of the body. In preserved specimens the male is coiled posteriorly in a spiral manner and measures about $14 \mathrm{~mm}$. in length. The female remains perfectly straight, measuring $22-26 \mathrm{~mm}$. $\times \cdot 3 \mathrm{~mm}$. The cuticle is thin and without transverse striation. At the posterior end of the male it expands to form a narrow ala on either side supported by the genital papillae. In the female its uniformity is disturbed only by a tiny pair of papillae near the tip of the tail.

The alimentary canal shows the usual differentiation into oesophagus, chyle intestine and rectum, the first-named structure presenting characters that associate Cystidicola with the other genera of the family Spiruridae. The mouth is a simple spherical orifice surmounted by two hook-like teeth that in shape recall the "external tooth " of Physaloptera species. It gives access to a deep cylindrical mouth capsule with thick 
chitinous wall measuring $1 \mathrm{~mm} . \times \cdot 01 \mathrm{~mm}$. The oesophagus is exceedingly long and narrow; it measures about $2.7 \mathrm{~mm} . \times 5 \mathrm{~mm}$; the anterior fifth is narrower than the succeeding portion and does not contain muscular fibres. The nerve ring encircles this slender part at its middle, i.e. about $3 \mathrm{~mm}$. from the anterior end of the body. The male genital system presents the following features : the testicular tube extends forwards without a single convolution from the cloaca along the ventral surface of the chyle intestine to end blindly at the junction of the anterior and posterior halves of the body. There are two spicules, unequal in size and thickness; the long slender spicule measures $75 \mathrm{~mm}$., the short one $\cdot 16 \times \cdot 025 \mathrm{~mm}$. The cloaca opens $\cdot 2 \mathrm{~mm}$. from the tip of the tail and is enclosed on either side by a narrow cuticular ala extending from the end of the body along each lateral edge to a similar distance in front of the cloacal orifice. Within the alae are seen a double series of nippleshaped papillae, there being nine pairs of prae-anal papillae and five single post-anal papillae in each ala. The components of the most anterior pair of prae-anals are considerably separated, whilst those of the other pairs lie close together, one slightly internal to the other.

The female genital system opens by a very short vagina in the centre of the ventral surface, midway between the head and tail.

From the vulva the vagina passes backwards, not forwards as stated by Schneider, for a distance equal to the diameter of the worm at that level and there divides into two uterine tubules, one of which continues directly backwards for a distance equal to a fourth of the body-length, doubling upon itself once in this distance in a coil of half that length and is then continued as an ovarian tubule. The other uterine tubule turns abruptly forwards from the vagina and describes a very similar course in the anterior region of the perivisceral cavity. Both ovarian tubules make two or three short coils. Those of the anterior tube only slightly overreach the junction of the oesophagus with the intestine, those of the posterior one do not extend so far as to encroach upon the posterior sixth of the body.

The mature female is ovoviparous, the eggs have thick shells with a curious tuft of exceedingly delicate filaments, two or three in number, attached to a small cuticular knob at either pole. The eggs measure $.0 \check{5} \times 025 \mathrm{~mm}$. and the shell is $005 \mathrm{~mm}$. thick. The only other nematode in which such filaments have been noted, to my knowledge, is Ascarophis morrhuae, van Beneden (1870)1, in which species there are cuticular appendages at one pole only.

1 van Beneden (1870), Les poissons des côtes de Belgique, Plate III. fig. 11. 